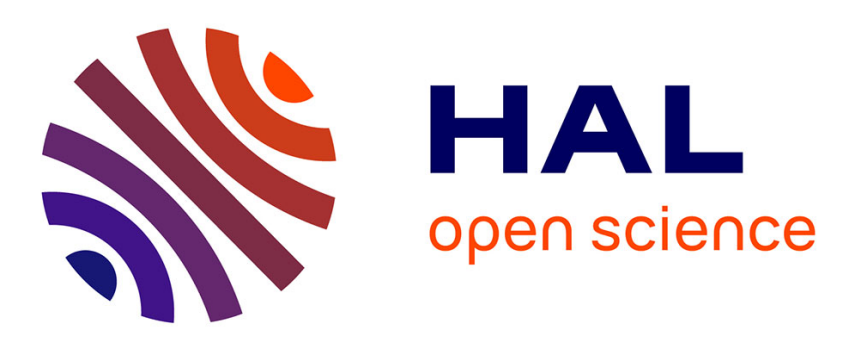

\title{
Precipitation mechanism of amorphous silica nanoparticles: a simulation approach
}

\author{
Claudine Noguera, B Fritz, A Clément
}

\section{To cite this version:}

Claudine Noguera, B Fritz, A Clément. Precipitation mechanism of amorphous silica nanoparticles: a simulation approach. Journal of Colloid and Interface Science, 2015, 448, pp.553-563. 10.1016/j.jcis.2015.02.050 . hal-01130231

\section{HAL Id: hal-01130231 \\ https://hal.sorbonne-universite.fr/hal-01130231}

Submitted on 11 Mar 2015

HAL is a multi-disciplinary open access archive for the deposit and dissemination of scientific research documents, whether they are published or not. The documents may come from teaching and research institutions in France or abroad, or from public or private research centers.
L'archive ouverte pluridisciplinaire HAL, est destinée au dépôt et à la diffusion de documents scientifiques de niveau recherche, publiés ou non, émanant des établissements d'enseignement et de recherche français ou étrangers, des laboratoires publics ou privés. 


\title{
Precipitation mechanism of amorphous silica nanoparticles: a simulation approach.
}

\author{
C.Noguera * ${ }^{*}, 2$ B. Fritz, ${ }^{3}$ and A. Clément ${ }^{3}$ \\ ${ }^{1}$ CNRS, INSP, UMR7588, F-75252 Paris Cedex 05, France \\ ${ }^{2}$ UPMC Univ Paris 06, INSP, UMR7588, F-75252 Paris Cedex 05, France \\ ${ }^{3}$ Université de Strasbourg/EOST,CNRS, Laboratoire d'Hydrologie et Géochimie de Strasbourg, \\ 1 rue Blessig, F-67084 Strasbourg Cedex, France
}

(Dated: February 25, 2015)

\begin{abstract}
Hypothesis: Despite its importance in numerous industrial and natural processes, many unsolved questions remain regarding the mechanism of silica precipitation in aqueous solutions: order of the reaction, role of silica oligomers, existence of an induction time and characteristics of the particle population. This may be traced back, in past models, to the lack of account of the first stages of nucleation, size dependence of the growth law, and full particle population.

Computational method: A microscopic description of the nucleation and growth of amorphous silica nanoparticles is achieved which reproduces a large set of experimental measurements, under various thermodynamic conditions. The time evolution of the solution supersaturation and of the precipitate characteristics is established.

Findings : A growth law of order 6 allows reproducing experimental results, without being correlated to the presence of silica oligomers in the aqueous solution. The saturation plateaus are shown not to be due to an induction period. The characteristics of the particle population are more complex than assumed by simple precipitation models (Johnson-Mehl-Avrami-Kolmogorov or Chronomal models) and strongly depend on how supersaturation is reached. Such a microscopic approach thus proves to be well suited to elucidate the mechanism of nanoparticle formation in natural and industrial contexts.
\end{abstract}

Keywords: nucleation and growth, computer simulation, NANOKIN code, amorphous silica, nanoparticles

\section{INTRODUCTION}

The precipitation of silica nanoparticles occurs in numerous industrial as well as natural processes. For example the formation of silica scales in deep geothermal wells represents a strong limitation to the possibility of extracting heat from high-temperature geothermal waters ${ }^{1}$. It also impacts subsurface contaminant remediation, underground radioactive wastes disposals, biomineralization and silicification processes among others ${ }^{2}$.

For these reasons, the mechanism of amorphous silica precipitation has been the subject of intensive research. Results obtained in laboratory have yielded precious information on the role of temperature, $\mathrm{pH}$, ionic strength and initial supersaturation ${ }^{2-10}$. The whole precipitation process is usually described as a succession of steps. First, silica monomers bind to each others to form small oligomers (dimers, trimers, tetramers, etc) in the aqueous solution, before, eventually, condensed spherical nanoparticles precipitate ${ }^{11-21}$. The first stage of monomer association is promoted by increasing the total aqueous $\left(\mathrm{SiO}_{2}\right)_{a q}$ concentration and by decreasing temperature. For the formation of solid particles, in some

*e.mail: claudine.noguera@insp.jussieu.fr tel: 33144274665 cases, the existence of an induction period is invoked, function of temperature and initial supersaturation ${ }^{2,4,7,8}$. It is followed by a stage, during which the degree of silica supersaturation strongly decreases, which allows the determination of global-reaction rates. Despite intensive studies, conflicting results have been obtained regarding the order of the global reaction, which varies from 1 to 8 , depending on the authors and the conditions of precipitation $^{22}$. In an ultimate stage, Ostwald ripening and aggregation may take place after $\left[\mathrm{H}_{4} \mathrm{SiO}_{4}\right]$ activity has reached the amorphous silica solubility limit.

It is noteworthy that, in most studies, only the time variation of the total silica aqueous concentration $\left(\mathrm{SiO}_{2}\right)_{a q}$ is recorded, making it difficult to fully characterize the precipitation mechanism, since information on the size distribution of the particles are missing. Thorough experiments performed on a time scale of 20-100 days, ${ }^{4}$ point out that the average molecular weight of the final particles increases from $10^{5}$ to $10^{9}$ molecular units as temperature is increased from 5 to $180^{\circ} \mathrm{C}$, which corresponds to an increase of the average particle-radii from $10 \mathrm{~nm}$ to $\approx 220 \mathrm{~nm}$. Experiments performed on much smaller time scales, rather find average radii of the order of a few $\mathrm{nm}^{7,8}$, in agreement with earlier speculations ${ }^{2}$. Only recently has Small Angle X-Ray Scattering (SAXS) been used to in-situ determine the time evolution of the mean particle sizes in precipitation experiments induced by neutralization of a high-pH silica solution or fast cooling, allowing a more complete description of the amorphous silica precipitation characteristics ${ }^{9,10}$.

It is thus timely to apply an advanced simulation technique to decipher the microscopic mechanism of amor- 
phous silica precipitation, beyond empirical approaches used in the past, such as simplified rate-equations $s^{4,7,8}$, the Johnson-Mehl-Avrami-Kolmogorov model ${ }^{9,10,23-25}$ or the Chronomal approach ${ }^{9,10,26}$. In the present computational approach, we demonstrate that use of the classical nucleation theory and of a size dependent growth law, as embedded in the NANOKIN code $\cos ^{27-30}$, allows a quantitative description of precipitation occurring under largely different experimental conditions : pre-established initial supersaturation ${ }^{4}$, supersaturation reached by neutralization of a high-pH silica solution ${ }^{9}$ or by fast cooling ${ }^{10}$. In particular, we are able to discard the hypothesis of an induction time as an explanation for the plateaus observed in the saturation curves in these experiments. We challenge the role of oligomer incorporation at the growth stage to account for the observed rate laws and we stress the difference between the order of the growth law and the order of the global reaction. We also demonstrate that the characteristics of the particle population are strongly dependent on the way supersaturation is reached.

The paper is organized as follows: after a description of the simulation method in Section II, we present results on the precipitation of amorphous silica particles under different conditions which correspond to increasing difficulties from the point of view of the simulation. We first consider precipitation induced by a pre-established initial supersaturation (Section III). We discuss the simulation set-up and the constraints which have to be fulfilled when fixing the nucleation and growth parameters. Then we compare our results to the experimental findings of Ref. 4. In Section IV, simulations mimicking precipitation processes induced by a fast neutralization or a fast cooling of an aqueous solution are discussed and their results are compared to those of Refs. 9 and 10. Section V addresses various issues raised by these simulations, in particular the possible role of oligomers in the aqueous solution during the precipitation process and the mechanism of amorphous silica precipitation. Section VI concludes.

\section{METHOD}

Our simulation of amorphous silica precipitation relies on the theoretical approach of nucleation, growth and/or dissolution of particles of fixed composition in aqueous solutions, that we have previously developed and which is embedded in the NANOKIN code ${ }^{27-29}$. It includes a full treatment of speciation processes in the aqueous solution according to published data base ${ }^{31,32}$, and a full account of nucleation and growth processes during the formation of new particles.

The supersaturation state $I$ of the aqueous solution with respect to the newly formed phase, defined as the ratio between the ortho-silicic acid activity $\left[\mathrm{H}_{4} \mathrm{SiO}_{4}\right]$ and the amorphous silica solubility product $K$, is the driving force for precipitation when $I>1$. The description of nucleation relies on the classical theory of nucleation (CNT), valid at small and moderate supersaturations ${ }^{33,34}$, in which critical nuclei are formed when the variation $\Delta G$ of the Gibbs' free energy for the condensation of $n$ gowth units is maximum with respect to $n$. The expression of $\Delta G$ :

$$
\Delta G=-n k_{B} T \ln I+4 \pi \rho^{2} \sigma
$$

assumes a spherical form for the critical nuclei, suited to amorphous silica particles ( $\rho$ their radius, $V$ their volume $V=4 \pi \rho^{3} / 3$ and $A$ their surface area $\left.A=4 \pi \rho^{2}\right) ; \sigma$ is the interface energy, $T$ the temperature and $k_{B}=R / \mathcal{N}_{A v}$ is related to the gas constant $R$ and the Avogadro number $\mathcal{N}_{A v}$. The number of growth units $n=V / v$ in the particle is determined by the ratio between its volume $V$ and the molecular volume $v$. The characteristics of the critical nuclei $n^{*}$ and $\rho^{*}$ are deduced from the condition that $\Delta G$ is maximum with respect to $n$ :

$$
n^{*}=\frac{2 u}{\ln ^{3} I} \quad ; \quad \rho^{*}=\frac{w}{\ln I}
$$

with:

$$
u=\frac{16 \pi \sigma^{3} v^{2}}{3\left(k_{B} T\right)^{3}} \quad ; \quad w=\frac{2 \sigma v}{k_{B} T}
$$

The nucleation rate $F$ is assumed to be an activated function of the nucleation barrier $\Delta G^{*}$ :

$$
\Delta G^{*}=k_{B} T \frac{u}{\ln ^{2} I}=\frac{1}{3} 4 \pi \rho^{* 2} \sigma
$$

with a constant pre-factor $F_{0}$ :

$$
F=F_{0} \exp \left(-\frac{\Delta G^{*}}{k_{B} T}\right)
$$

$F$ is a highly non linear function of $I$ which exceeds the value of 1 particule $/ \mathrm{s} / \mathrm{kg}$ of water, if $I$ is larger than a critical value $I_{c}$ equal to :

$$
\ln I_{c}=\sqrt{\frac{u}{\ln F_{0}}}
$$

The simulation relies on a technique of time discretization. At each time step, a new class of particles is created if $I>I_{c}$ and, once formed and as the saturation state of the solution evolves with time, the particles experience growth or dissolution, depending upon the relative value of their radius compared to the instantaneous critical nucleus radius $\rho^{*}$ :

$$
\frac{d \rho}{d t}=\kappa\left[I^{m}-\exp \left(\frac{m w}{\rho}\right)\right]
$$

In this equation, $\kappa$ is the particle radius growth constant and $m$ is an integer number defining the order of the growth reaction. This $m$ exponent should not be confused with the order $n$ of the global "reaction rate" often empirically written $d Q / d t=K(I-1)^{n}(Q$ the 
total amount of precipitate). Here, we do not presuppose an analytic form for $d Q / d t$. The time dependence of $Q(t)$ results from a complex interplay between nucleation/growth and dissolution processes that are driven by equations 2-5 for nucleation and 7 for growth and dissolution. Written under this form, Equation 7 describes a surface controlled growth mechanism and allows Ostwald ripening effects to occur (its right hand side is positive or negative according to whether $\rho>\rho^{*}$ or $\rho<\rho^{*}$, respectively $)^{35-37}$. When the number of growth units in particles belonging to a given class becomes less than unity, the class is suppressed.

At each time $t$, the knowledge of the total amount of precipitate allows to update the ion concentrations and activities in the aqueous solution, by resolution of the speciation equations, and the value of the saturation state of the aqueous solution is recalculated. Unless specified, only monomeric silicate species are taken into account. The above equations describe processes in which the system is prepared in a pre-established initial supersaturation state. In Section III, the results will be compared to the experiments performed in Ref. 4.

We also simulate the precipitation of amorphous silica induced by neutralization of a high-pH aqueous solution or by fast cooling, and, in section IV, we compare our results with the experiments performed in Refs. 9 and 10 , respectively. A time dependence of $\mathrm{pH}$ or temperature is assumed during a finite time interval (a few minutes) before their values stabilize at normal conditions (neutral $\mathrm{pH}$ or $\mathrm{T}=30^{\circ} \mathrm{C}$ ). In the former case, the $\mathrm{pH}$ drop modifies the activities of the aqueous silicate species, in particular the $\left[\mathrm{H}_{4} \mathrm{SiO}_{4}\right]$ to $\left[\mathrm{H}_{3} \mathrm{SiO}_{4}^{-}\right]$ratio, according to the speciation equations, and thus increases the saturation state of the aqueous solution. In the latter case, the temperature dependence of the amorphous silica solubility is the driving force to reach supersaturation. Specific details are given in Section IV.

Compared to empirical models used in the past (simplified rate equations, the Johnson-Mehl-AvramiKolmogorov model ${ }^{23-25}$ or the Chronomal approach ${ }^{26}$ ), the present formalism fully accounts for all processes possibly taking place at each time step, without assuming that nucleation, growth, and ripening occur sequentially. Since it follows the size variation of all particle classes that have been nucleated, it is able to yield thorough information on the time evolution of the particle population, for example the mean particle size, as well as of the aqueous solution composition.

\section{SIMULATION OF PRECIPITATION AT PRE-ESTABLISHED INITIAL SUPERSATURATION}

In this section, we present simulations of the precipitation of amorphous silica particles induced by a preestablished initial supersaturation of the aqueous solution at constant temperatures, to be compared to results given in Ref. 4. In this work, a thorough investigation of the time evolution of the saturation state of an aqueous solution, during the precipitation of amorphous silica was performed, at neutral $\mathrm{pH}$, various temperatures (from $\mathrm{T}=5^{\circ} \mathrm{C}$ to $\mathrm{T}=180^{\circ} \mathrm{C}$ ) and various initial silica contents $c_{\mathrm{SiO}_{2}}$. Typical results are reproduced in Figure 1. Their common characteristics is the existence of a plateau, associated to a constant $\mathrm{H}_{4} \mathrm{SiO}_{4}$ concentration in the aqueous solution, before supersaturation starts decreasing. The plateaus were interpreted as induction periods for precipitation. The authors found that the fourth root of their length $\Delta t$ decreases approximately linearly as the initial $c_{\mathrm{SiO}_{2}}$ increases. A similar fourth order law was found for the variation of the maximum "reaction rate" with initial $\mathrm{H}_{4} \mathrm{SiO}_{4}$ concentration, the maximum reaction rate being defined as the maximum slope of the saturation curve after the plateau.

We first describe the procedure that is followed to determine the nucleation and growth parameter values, necessary to perform the simulations. Then we compare the simulation results to the results of Ref. 4. The justification of assuming a pre-established supersaturation to interpret the results of Ref. 4 will be given at the end of Section IV B.

\section{A. Simulation set-up}

Within the formalism developed in Section II, aside from tabulated values of the amorphous silica solubility ${ }^{31,32,38}$ and molecular volume $v=48.15 \AA^{3}$, a set of nucleation and growth parameters $\left\{\sigma, F_{0}, \kappa, m\right\}$ is needed at each temperature to perform the simulations.

We have determined the values of these parameters at five temperatures: $T=5^{\circ} \mathrm{C}, 30^{\circ} \mathrm{C}, 60^{\circ} \mathrm{C}, 90^{\circ} \mathrm{C}$ and $120^{\circ} \mathrm{C}$, by searching for the best agreement with the results of Ref. 4. The fitting procedure is highly non-linear, with no certitude that a unique solution exists. However, it is possible to reduce the range of admissible parameter values, by first analyzing the constraints that they have to fulfill.

\section{Constraints on the nucleation parameters $\sigma$ and $F_{0}$}

Within the assumptions underlying the CNT, nucleation significantly occurs only when the saturation state of the aqueous solution exceeds a critical value $I_{c}$ function of $F_{0}$ and $\sigma$ (Equation 6 ). For each temperature, it is thus obvious that $I_{c}$ has to be lower than the lowest initial supersaturation (called $I_{0 \min }$ in Table 1 ) considered in Ref. 4 for which precipitation occurs. $I_{c}<I_{0 \min }$ thus represents a first constraint to be fulfilled by $\sigma$ and $F_{0}$.

Additionally, the plateau lengths $\Delta t$ are strongly dependent on $I_{c}$. As $I_{c}$ increases, those associated to the smallest supersaturations increase much more than those associated to highest ones. The fine tuning of the relative 

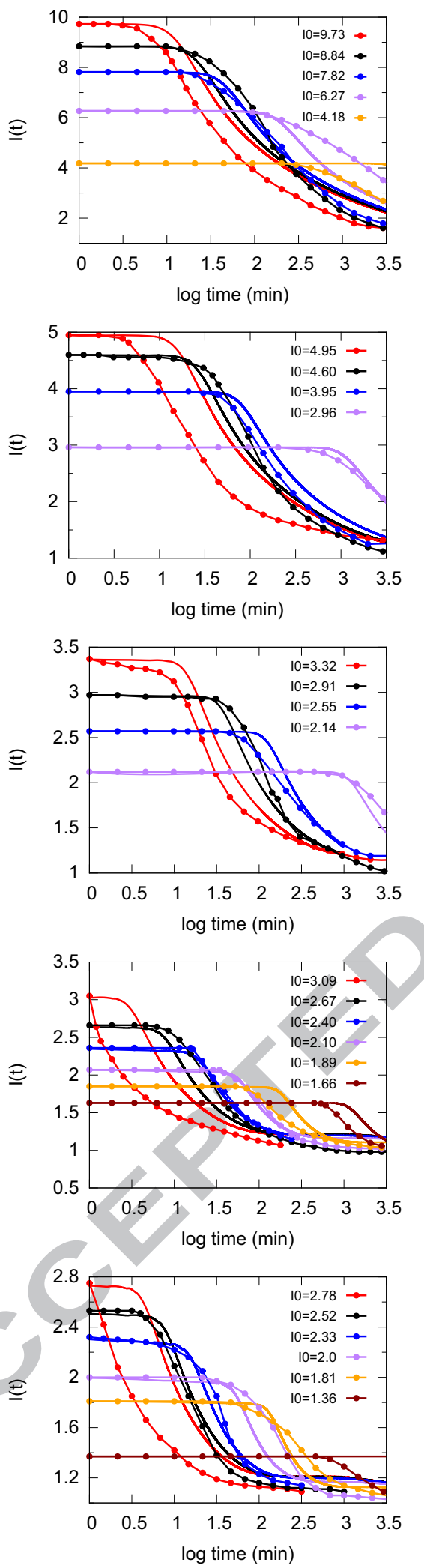

FIG. 1: Time evolution of the saturation state $I$ of the aqueous solution during amorphous silica precipitation at constant temperatures (logarithmic scale for time expressed in minutes). From top to bottom $T=5^{\circ} \mathrm{C}, 30^{\circ} \mathrm{C}, 60^{\circ} \mathrm{C}, 90^{\circ} \mathrm{C}$ and $120^{\circ} \mathrm{C}$. Lines are simulation results while lines-points are experimental results read from Ref. 4. In each case, initial saturation values $I_{0}$ are those of Ref. 4.

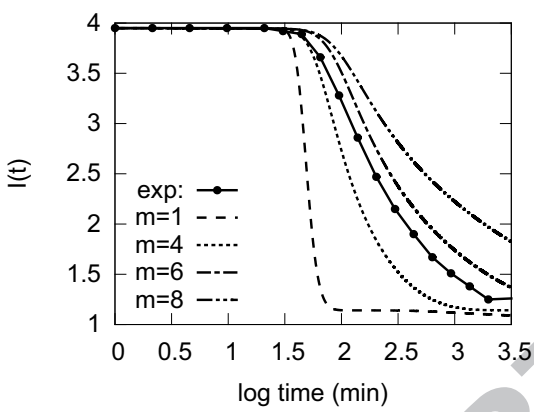

FIG. 2: Time variation of the saturation state of the aqueous solution for various values $m=1,4,6$ and 8 of the growth rate exponent (logarithmic scale for time expressed in minutes). $\mathrm{T}=30^{\circ} \mathrm{C}$ and $I_{0}=3.95$. For each value of $m$, the growth constants $\kappa$ are adjusted so as to yield the experimentally observed plateau length ${ }^{4}$ (represented by lines-points symbols).

plateau lengths thus puts an additional constraint on $I_{c}$, i.e. on the determination of $F_{0}$ and $\sigma$.

As far as $F_{0}$ is concerned, no useful hint for its value may be obtained from the literature. Discrepancies as high as ten orders of magnitude are reported ${ }^{34,39}$. We have thus assumed that it is independent on temperature and fixed its value to $10^{19}$ particles $/ \mathrm{s} / \mathrm{kg} \mathrm{H} \mathrm{H}_{2} \mathrm{O}$, which is in the average expected range and yields reasonable particle sizes. There is not a high sensitivity of the saturation curves to this parameter, as specified below.

Introducing this value for $F_{0}$ into Equation 6 , the condition $I_{c}<I_{0 \min }$ puts an upper limit $\sigma_{\max }$, given in Table 1 , to the interface energy $\sigma$. The values of $\sigma_{\max }$ are not strongly dependent on $F_{0}$ : indeed, changing $F_{0}$ by two orders of magnitude, only modifies $\sigma_{\max }$ by $\approx 1.5$ $\mathrm{mJ} / \mathrm{m}^{2}$.

\section{Constraints on the growth parameters $m$ and $\kappa$}

Reproducing the shape of the saturation curves, the length $\Delta t$ of the plateaus and the decrease of supersaturation after the plateau imposes strong constraints on the growth parameters $m$ and $\kappa$ (Equation 7).

We have found that, whatever the initial supersaturation value, $\Delta t$ is inversely proportional to $\kappa$. This means that, at a given temperature, increasing or decreasing $\kappa$ proportionally modifies all $\Delta t$, but does not change their relative values. This latter quantity is rather determined by the ratio $I_{0} / I_{c}$, as already said.

Moreover, a competition between nucleation and growth determines the shape of the saturation curves, in particular, at the very beginning of precipitation. When nucleation is very efficient, a nearly instantaneous decrease of supersaturation takes place. A detailed account of the physical processes occurring in that case can be found in one of our previous works (scenario \#1 in Ref. 28). In the experiments upon consideration here, the ex- 


\begin{tabular}{|l||c|c||c||c|c|c|}
\hline $\mathrm{T}\left({ }^{\circ} \mathrm{C}\right)$ & $I_{0 \min }$ & $\sigma_{\max }\left(\mathrm{mJ} / \mathrm{m}^{2}\right)$ & $\kappa_{\min }(\mathrm{m} / \mathrm{s})$ & $K(\mathrm{mM} / \mathrm{l})$ & $\sigma\left(\mathrm{mJ} / \mathrm{m}^{2}\right)$ & $\kappa(m / s))$ \\
\hline 5 & 4.18 & 51 & $1.9^{*} 10^{-18}$ & 1.16 & 36 & $4 .^{*} 10^{-18}$ \\
30 & 2.96 & 46 & $1.3^{*} 10^{-16}$ & 2.16 & 32 & $2 .^{*} 10^{-16}$ \\
60 & 2.12 & 40 & $1.8^{*} 10^{-15}$ & 3.66 & 28 & $2 .^{*} 10^{-15}$ \\
90 & 1.63 & 33 & $1.2^{*} 10^{-14}$ & 5.57 & 23 & $1.3^{*} 10^{-14}$ \\
120 & 1.37 & 26 & - & 7.87 & 23 & $1.7^{*} 10^{-14}$ \\
\hline
\end{tabular}

TABLE 1: Left part of the table: For each temperature $T$, lowest initial supersaturation $I_{0 \min }$ in the experiments of Ref. 4 for which precipitation occurs and deduced maximum value $\sigma_{\max }$ of the interface energy, assuming $F_{0}=10^{19} \mathrm{particles} / \mathrm{s} / \mathrm{kg}$ $\mathrm{H}_{2} \mathrm{O}$. Central part of the table: minimum value $\kappa_{\min }$ of the growth rate constant $\kappa$ required for the saturation curve to display a well-defined plateau. No value is given when $\mathrm{T}=120^{\circ}$, since the saturation curves display a plateau, whatever the $\kappa$ value. Right part of the Table: Parameters used in the simulations at various temperatures T: $K$ the amorphous silica solubility product, $\sigma$ the interface energy and $\kappa$ the growth rate constant entering Equation 7; these values are associated to $m=6$ and $F_{0}=10^{19}$ particles $/ \mathrm{s} / \mathrm{kg} \mathrm{H} \mathrm{O}_{2}$.

istence of saturation plateaus from the beginning of precipitation points towards the prevalence of growth upon nucleation. Consequently, at constant values of the nucleation parameters, $\kappa$ has to exceed some critical value $\kappa_{\text {min }}$. Taking into account the values of $F_{0}$ and $\sigma$ at the temperatures upon consideration, Table 1 gives the values $\kappa_{\min }$ required for the saturation curve to display a well-defined plateau.

The saturation decrease after the plateau strongly depends on the growth rate exponent $m$. Figure 2 displays a typical example $\left(\mathrm{T}=30^{\circ} \mathrm{C}\right.$ and $\left.I_{0}=3.95\right)$, showing how, with $\kappa$ values adjusted as to yield the correct plateau length, the slope of the saturation curve (maximum "reaction rate") smooths out when $m$ increases. By comparing these curves to the experimental results of Ref. 4 , we have found that $m=6$ is the value which yields the best agreement with most experimental curves at all temperatures upon consideration. In particular, it is impossible to account for both the plateau length and the supersaturation decrease with an exponent $m=1$ in the growth law.

\section{B. Results}

Considering all the above mentioned constraints which reduce the range of admissible values of $\left\{\sigma, F_{0}, \kappa, m\right\}$, we have proceeded by trial and error to fix them at all temperature, in order to best account visually for the results of Ref. 4. They are listed in Table 1, together with the amorphous silica solubility and are complemented by the choice $m=6$ and $F_{0}=10^{19}$ particles $/ \mathrm{s} / \mathrm{kg} \mathrm{H}_{2} \mathrm{O}$. They will be discussed in Section VA.

Figure 1 compares the time evolution (in log scale) of the saturation state of the aqueous solution obtained experimentally ${ }^{4}$ and numerically, in a time range of $\approx$ 3000 minutes, at $\mathrm{T}=5^{\circ} \mathrm{C}, 30^{\circ} \mathrm{C}, 60^{\circ} \mathrm{C}, 90^{\circ} \mathrm{C}$ and $120^{\circ} \mathrm{C}$. Although the agreement between experimental and simulation results is not perfect, the qualitative and, in a number of cases, the quantitative trends are correctly reproduced. This is true, in particular, for the variations of the plateau length and of the maximum "reaction rate" as a function of $I_{0}$. The most obvious discrepancy is the slight overestimation of the plateau lengths at the highest initial supersaturations. It is accentuated in the representation of Fig. 1 due to the time log scale, but this overestimation never exceeds a few minutes.

The agreement between simulations and experiments actually decreases as temperature increases beyond $\mathrm{T}=90^{\circ}$. We assign this degradation to the fact that the aqueous solutions become supersaturated with respect to less soluble $\mathrm{SiO}_{2}$ phases such as cristobalite or quartz, which thus may compete with the precipitation of amorphous silica. Such a competition is well-known to take place in hydro-thermal solutions. In the temperature range $150-200^{\circ} \mathrm{C}$, the $\mathrm{H}_{4} \mathrm{SiO}_{4}$ concentration is indeed used as a good geothermometer due to equilibrium with quartz for long term reactions in geological conditions ${ }^{40}$. Although in lab experiments, time scales may not allow to reach equilibrium, the risk of quartz precipitation is nevertheless non-negligible when $\mathrm{T}$ increases ${ }^{41}$. Indeed, in Ref. 4 , in the temperature range $150-180^{\circ} \mathrm{C}$, the concentrations of $\mathrm{H}_{4} \mathrm{SiO}_{4}$ become lower than the amorphous silica solubility at long times and this is also true at $T=120^{\circ} \mathrm{C}$ in one of the saturation curves. Since the possibility of simultaneous precipitation of two minerals is not considered in our simulations, we have not tried to reproduce the experimental results at $\mathrm{T}=150^{\circ} \mathrm{C}$ nor at $\mathrm{T}=180^{\circ} \mathrm{C}$.

Aside from the time dependence of the saturation, the simulations give information on the mean particle sizes. The largest particle sizes are obtained for the lowest initial supersaturation values. At final times of the Rothbaum and Rohde's experiments $(t \approx 70$ days $)$, the mean particle radii amount to $\approx 10 \mathrm{~nm}$ for $5^{\circ} \mathrm{C} \leq T \leq 90^{\circ} \mathrm{C}$ and $\approx 400 \mathrm{~nm}$ for $T=120^{\circ} \mathrm{C}$. This is qualitatively consistent with the estimate of $10^{5}$ to $10^{9}$ formula units given in Ref. 4. 


\section{SIMULATION OF THE PRECIPITATION INDUCED BY NEUTRALIZATION OR COOLING OF A SILICA-RICH SOLUTION}

This section deals with more complex simulations in which the aqueous solution is not initially prepared in a supersaturated state, but reaches supersaturation as the result of time-dependent modifications of its thermodynamic state ( $\mathrm{pH}$ or temperature). Such simulations are more demanding than those performed in Section III since they require an account of these time-dependent changes, not always precisely known experimentally. Experiments of this type, using modern characterization tools, have brought interesting information on the evolution of not only the aqueous solution state but also the mean particle sizes ${ }^{9,10}$. The two following subsections describe our attempts to account for amorphous silica precipitation under conditions of varying $\mathrm{pH}$ and temperature, in link with the experimental results of Ref. 9 and 10 , respectively.

\section{A. Simulation of a precipitation induced by neutralization of a high-pH silica solution}

In Ref. 9, aqueous solutions with two different initial silica contents $\left(c_{\mathrm{SiO}_{2}}=640 \mathrm{ppm}\right.$ and $\left.1600 \mathrm{ppm}\right)$ were prepared at $\mathrm{pH}=12$ and $\mathrm{T}=25^{\circ} \mathrm{C}$, before silica precipitation was induced by neutralization. The data acquisition started once the $\mathrm{pH}$ had stabilized at 7 , i.e. within approximately $5 \mathrm{~min}$. The time evolution of the saturation state of the aqueous solution and of the mean particle radius, reproduced from Ref. 9, are represented in Fig. 3 with lines-points on a linear scale for the time axis.

In our simulation, we have tested several laws for the variation of $\mathrm{pH}$ between $\mathrm{pH}=12$ and $\mathrm{pH}=7$ : a linear decrease during a time $\tau=5$ min followed by constant $\mathrm{pH}=7$, and exponential laws of the type $\mathrm{pH}(t)=7+$ $5 \exp (-t / \tau)$ with various values for the characteristic time $\tau$. This constraint on $\mathrm{pH}$ imposes a time variation of the speciation of silica in the aqueous solution. In the absence of information on the variation of the nucleation and growth parameters $\left\{\sigma, F_{0}, \kappa, m\right\}$ with $\mathrm{pH}$, we have assumed that they are independent on $\mathrm{pH}$. We have used their $\mathrm{T}=30^{\circ} \mathrm{C}$ values, assuming that their variations between $\mathrm{T}=30^{\circ} \mathrm{C}$ and $\mathrm{T}=25^{\circ} \mathrm{C}$ are negligible.

Contrary to the simulated saturation curves obtained with a pre-established supersaturation, those shown in Figure 3 display a maximum. The increase of saturation which occurs at short times corresponds to the neutralization phase. The saturation value at the maximum of the curve is slightly smaller than the maximum saturation expected at neutral $\mathrm{pH}$ from the initial silica content. This shows that nucleation has not been very important during the neutralization phase. However, the saturation state of the aqueous solution and the mean particle radius curves are somewhat sensitive to the assumption made for the $\mathrm{pH}$ variation. In Fig. 3, are represented

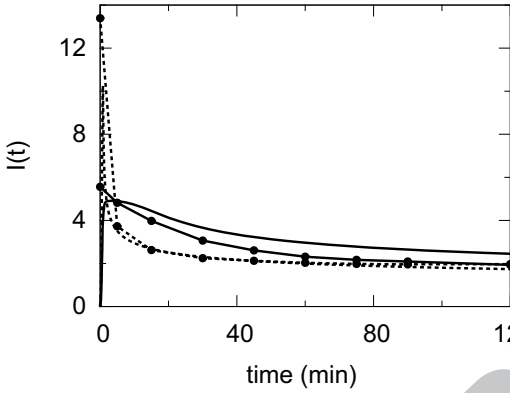

120

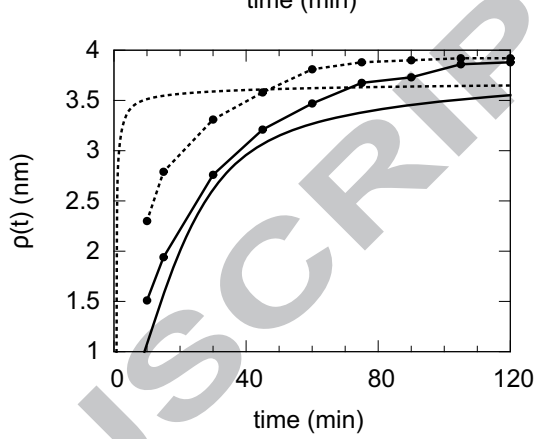

FIG. 3: Precipitation of amorphous silica in a neutralization experiment (see text). Top panel: time evolution (in min) of the saturation state $I$ of the aqueous solution; bottom panel: time evolution of the mean particle radius $\rho$ (in $\mathrm{nm}$ ). Lines are simulation results while lines-points are experimental results read from Ref. 9. Full lines: $c_{\mathrm{SiO}_{2}}=640 \mathrm{ppm}$; dotted lines: $c_{\mathrm{SiO}_{2}}=1600 \mathrm{ppm}$

those which present the best agreement with experiment. They have been obtained with the exponential time variation of $\mathrm{pH}$ with $\tau=1 \mathrm{~min}$, for which $\mathrm{pH}=7.03$ at $t=5$ min, in qualitative agreement with the experimental protocol. The experimental and simulation curves display an overall good agreement ${ }^{42}$, even if the particle sizes at $c_{\mathrm{SiO}_{2}}=1600 \mathrm{ppm}$ grow too quickly in the simulation. The simulated maximum particle radii obtained after two hours are extremely close to the experimental ones. At variance, when a linear dependence of $\mathrm{pH}$ upon time is assumed, simulated particle radii are slightly larger for $c_{\mathrm{SiO}_{2}}=640 \mathrm{ppm}$ than for $c_{\mathrm{SiO}_{2}}=1600 \mathrm{ppm}$, in disagreement with experiment.

\section{B. Simulation of a precipitation induced by fast cooling}

In Ref. 10, aqueous solutions with two different initial silica contents $\left(c_{\mathrm{SiO}_{2}}=640 \mathrm{ppm}\right.$ and $\left.960 \mathrm{ppm}\right)$ were prepared at $\mathrm{T}=230^{\circ} \mathrm{C}$. Then amorphous silica precipitation was induced by fast cooling down to ambient temperature $T=30^{\circ} \mathrm{C}$ within 2-3 minutes, to mimic geothermal conditions. Similarly to the $\mathrm{pH}$ experiments, both the time evolution of the aqueous solution composition and the mean size of the silica nanoparticles were recorded, 
thanks to in-situ SAXS experiments. The experimental results are reproduced in Figure 4. The first SAXS measurements were performed at $t=10 \mathrm{~min}$, and, for the lowest initial silica content, particles could only be detected after $60 \mathrm{~min}$. This time was interpreted as a an induction time.

We have performed a more involved simulation of precipitation under cooling conditions than when the $\mathrm{pH}$ varies. First, since, in Ref. 10, the way temperature decreases during the cooling process wais not precisely determined, we have tested several laws which will be specified below. Second, many physico-chemical parameters vary with temperature. They include the amorphous silica solubility product, the dissociation constants and the activity coefficients of the aqueous species, whose variations can be straightforwardly obtained from the data bases associated to NANOKIN. Additionally, the nucleation and growth parameters $\sigma$ and $\kappa$ depend on temperature, as found in Section III. We have taken these variations into account, by an interpolation procedure between $\mathrm{T}=30^{\circ} \mathrm{C}$ and $\mathrm{T}=120^{\circ} \mathrm{C}$. Beyond $\mathrm{T}=120^{\circ} \mathrm{C}$, we have extrapolated their dependence by relying on more general arguments (see Section V.A). We have checked that the precipitation characteristics were little affected by this extrapolation, by making it in several ways, but they all led to very similar results. The reason may be easily understood: during the cooling period, nucleation only occurs after the saturation state of the aqueous solution has exceeded the critical value $I_{c}$ which, here, is close to $\approx 1.9$. This does not take place at $\mathrm{T}=230^{\circ} \mathrm{C}$, but at a much lower temperature, close to $\mathrm{T}=100^{\circ} \mathrm{C}$ when $c_{\mathrm{SiO}_{2}}=$ $640 \mathrm{ppm}$ and close to $\mathrm{T}=160^{\circ} \mathrm{C}$ when $c_{\mathrm{SiO}_{2}}=960 \mathrm{ppm}$. The values of $\sigma$ and $\kappa$ above these temperatures, which are the most uncertain, are thus irrelevant.

Figure 4 displays the results obtained under the assumption of an exponential cooling rate $\mathrm{T}(t)=30+$ $200 \exp (-t / \tau)$ with $\tau=60 \mathrm{~s}\left(\mathrm{~T}\right.$ in $\left.{ }^{\circ} \mathrm{C}\right)$ and with the values $F_{0}$ and $m$ used in Section III. The agreement is excellent as far as the time evolution of the saturation state of the aqueous solution is concerned ${ }^{42}$. The predicted maximum particle sizes are in the right range but their evolution is too fast. No 'induction time' is found for $c_{\mathrm{SiO}_{2}}=640 \mathrm{ppm}$, and the larger $c_{\mathrm{SiO}_{2}}$ yields the smallest particles, in qualitative disagreement with experiment.

We have then checked the influence of the cooling law. Relying on the experimental information that ambient temperature is reached in about three minutes, we have considered the following time dependencies of the temperature:

$$
\begin{array}{r}
T_{1}=30+200 *(1-t / \tau) ; \tau=180 s \\
T_{2}=30+200 * \exp \left(-t^{4} / \tau^{4}\right) ; \tau=20 s \\
T_{3}=30+200 * \exp \left(-t^{2} / \tau^{2}\right) ; \tau=100 s \\
T_{4}=30+200 * \exp (-t / \tau) ; \tau=60 s \\
T_{5}=30+200 * \exp (-\sqrt{t / \tau}) ; \tau=20 s
\end{array}
$$

with the decrease of $T_{1}$ limited at $\mathrm{T}=30^{\circ} \mathrm{C}$ for $t>\tau$. The
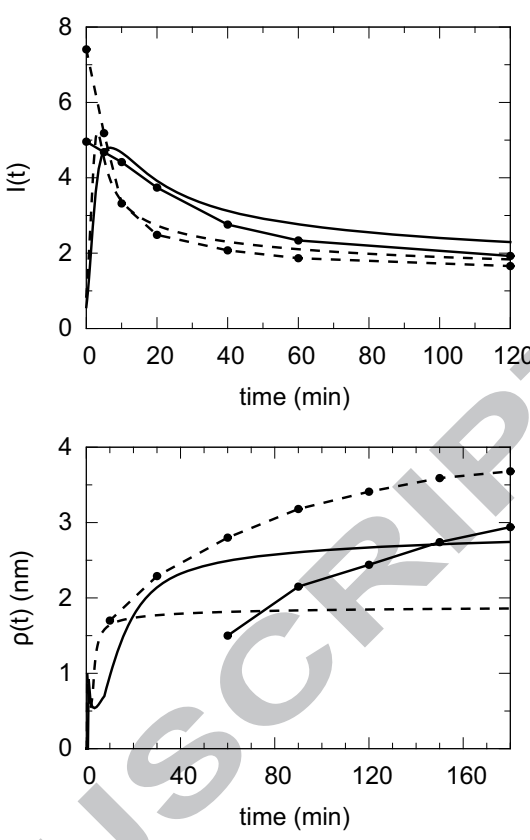

FIG. 4: Precipitation of amorphous silica in a cooling experiment (see text) : top panel: time evolution (in min) of the saturation state $I$ of the aqueous solution; bottom panel: time evolution of the mean particle radius $\rho$ (in $\mathrm{nm}$ ). Lines are simulation results while lines-points are experimental results read from Ref. 10. Full lines: $c_{\mathrm{SiO}_{2}}=640 \mathrm{ppm}$; dashed lines: $c_{\mathrm{SiO}_{2}}=960 \mathrm{ppm}$.

various values of $\tau$ have been chosen in such a way that all $T_{n}$ reach approximately $40^{\circ} \mathrm{C}$ at the same time $(t \approx 170$ $\mathrm{s})$, but the expected ambient temperature $T=30^{\circ} \mathrm{C}$ is reached more and more slowly down the series. We have found that the saturation curves are little affected by the choice of the cooling law, but the final particle radii, at time $t=180 \mathrm{~min}$, may vary by as much as a factor of 2 , as shown in Table 2 (left part). In the right part of the Table, we also give the values of the final particle radii for a Gaussian law with various characteristic times $\tau$. The same extreme sensitivity to the cooling speed is found. In addition, for extremely fast cooling rates $(\tau \leq 3 \mathrm{~s}), \rho_{640}$ becomes smaller than $\rho_{960}$, as in the experiment. We presently do not understand well why the experimental size ordering can only be reproduced under such fast cooling conditions.

Beyond the interest in reproducing the results of Ref. 10 , it is instructive to analyze under which conditions the cooling and precipitation stages are well-separated. For this to be true, it is necessary that particles do not nucleate in a significant amount during the cooling time. When this is the case, the maximum of the saturation curve is close to the maximum saturation expected at $\mathrm{T}=30^{\circ}$ from the initial silica content $\left(I=7.4\right.$ for $c_{\mathrm{SiO}_{2}}=$ $960 \mathrm{ppm}$ and $I=4.95$ for $c_{\mathrm{SiO}_{2}}=640 \mathrm{ppm}$ ). From Figure 4 , it is obvious that this condition is not fulfilled when 


\begin{tabular}{|l|l|l||l|c|c|}
\hline$T_{n}$ & $\rho_{640}$ & $\rho_{960}$ & $\tau$ & $\rho_{640}$ & $\rho_{960}$ \\
\hline$T_{1}$ & 5.5 & 2.0 & 100 & 3.3 & 1.9 \\
$T_{2}$ & 6.8 & 3.5 & 20 & 5.0 & 2.8 \\
$T_{3}$ & 3.3 & 2.0 & 5 & 7.4 & 4.0 \\
$T_{4}$ & 2.7 & 1.9 & 2 & 4.7 & 5.4 \\
$T_{5}$ & 2.5 & 1.9 & 1 & 4.2 & 6.5 \\
\hline
\end{tabular}

TABLE 2: Particle radii (in $\mathrm{nm}$ ) in the simulations starting with silica contents $c_{\mathrm{SiO}_{2}}=640 \mathrm{ppm}$ and $c_{\mathrm{SiO}_{2}}=960 \mathrm{ppm}$, obtained at time $t=180 \mathrm{~min}$. Left: for the various temperature laws, Eq. 8; Right: for a Gaussian law with various characteristic times $\tau$.

$c_{\mathrm{SiO}_{2}}=960 \mathrm{ppm}$, while the experiment with $c_{\mathrm{SiO}_{2}}=640$ ppm seems to be at the border line. We have performed similar simulations at even lower silica contents. In these cases, we find that the amount of solid phase precipitated during the cooling period is negligible with respect to the initial silica content (typically less than 1\%). This was to be expected since, as $c_{\mathrm{SiO}_{2}}$ decreases, according to Equations 4 and 5, the nucleation frequency strongly decreases. For small initial silica contents, the cooling and nucleation processes are thus well-separated in time and a simulation assuming a pre-established supersaturation and a constant $\mathrm{T}=30^{\circ}$ temperature is valid. The experiments performed in Ref. 4 pertain to this last case due to the low initial silica content (equal or lower than those of Ref. 10), although the experimental protocol includes a rapid cooling of the aqueous solution from $240-265^{\circ} \mathrm{C}$. This justifies our assumption of a constant temperature and a pre-established supersaturation in Section III, which allowed us to disentangle the determination of the nucleation and growth parameters at the various temperatures.

\section{DISCUSSION}

After a discussion of the parameter values, this section focuses on several issues related to the simulations presented above. The first one regards the possible influence of silica oligomers in the aqueous solution, during the formation of silica nanoparticles in the conditions prevailing in the experiments under consideration. Then we discuss the information brought by our approach on the mechanism of amorphous silica formation, in the various thermodynamic conditions considered in the present work.

\section{A. Discussion of the parameter values}

The values of $\left\{\sigma, F_{0}, \kappa\right\}$ that we have determined and which are listed in Table 1 deserve several comments.

One is linked to the sensitivity of the results to small variations around these values. Since small modifications of the shapes of the saturation curves are not easily
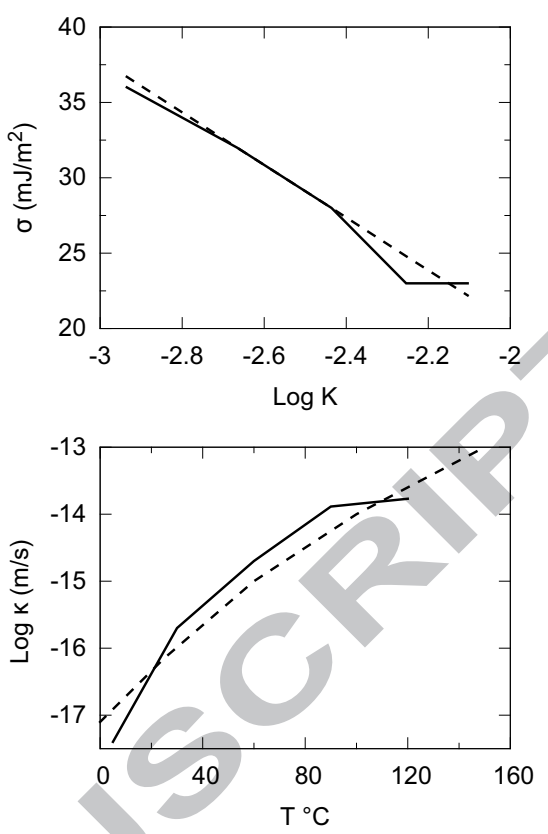

FIG. 5: Top panel: Correlation between $\sigma$ values (in $\mathrm{mJ} / \mathrm{m}^{2}$ ) and values of the amorphous silica solubility product $K$ (log scale) at various temperatures. Full line: $\sigma$ values determined in the present work; Dashed line: correlation deduced from Ref. 48. Bottom panel: Full line: Temperature variation of the growth constant $\kappa$ (log scale) determined from the fit with the experiments performed in Ref. 4. The dashed line shows an activated temperature dependence with an activation energy $E_{a}=60 \mathrm{~kJ} / \mathrm{mole}$.

quantified, we have chosen to focus on the sensitivity of the plateau lengths $\Delta t$. In this respect, similar relative variations of $\sigma, F_{0}$ and $\kappa$ induce quantitatively different effects. For example at $T=30^{\circ} \mathrm{C}$, changing $\kappa$ by $\pm 10 \%$ modifies $\Delta t$ by $\mp 7-8 \%$, while a similar variation on $F_{0}$ only modifies $\Delta t$ by $\mp 2-3 \%$. The sensitivity to $\sigma$ variations is much larger and strongly dependent on $I_{0}$. Increasing $\sigma$ by $2 \mathrm{~mJ} / \mathrm{m}^{2}$ increases $\Delta t$ by $\approx 40 \%$ when $I_{0}=4.95$ and by $\approx 100 \%$ when $I_{0}=2.96$. This shows that, while $\sigma$ is highly constrained, due the $\sigma^{3}$ factor in the exponential of the nucleation rate, the determined values of $\kappa$ and $F_{0}$ should be understood with a precision which certainly does not exceed $10-20 \%$.

Moreover, it is striking that the determined $\sigma$ values are lower than the values usually quoted in the literature ${ }^{2}$ for amorphous silica, which are of the order of $80 \mathrm{~mJ} / \mathrm{m}^{2}$. On the one hand, this may be due to the hydrated and porous nature of the nanoparticles. It is known that water molecules are easily incorporated in small nuclei under formation, especially in amorphous ones, as noted by several authors ${ }^{9,43}$. This was, for example, evidenced by a decrease of the particle radii in the high vacuum of scanning or transmission electron microscopy apparatus in Ref. 9. When water penetrates into a lattice, it 
decreases its cohesion and, as a consequence, the work necessary to create surfaces is reduced. Furthermore, it is a general trend that interface energies of particles in contact with water are much lower than those of dry particles $^{44-46}$. To the best of our knowledge, there are no tabulated values of hydration energies of amorphous silica as a function of temperature, that we could have used to estimate $\sigma$, or compare to the values that we have determined. On the other hand, the experiments under consideration are performed at neutral $\mathrm{pH}$, i.e. far from the point of zero charge of amorphous silica which is close to 2. The particle surfaces are thus charged and this is known to decrease the oxide-solution interfacial tension $^{47}$.

The $\sigma$ values that we have determined significantly decrease when temperature is raised. This is in qualitative agreement with the quasi-linear dependence of interface energies on the logarithm of solubilities, highlighted in the work of Nielsen and Söhnel ${ }^{48}$. We have reproduced this relationship in Figure 5 (top panel) together with the $\sigma$ values that we have determined. A very good agreement is found, giving support to our procedure. The $\kappa$ values also strongly vary with temperature. They increase by several orders of magnitude between $\mathrm{T}=5^{\circ}$ and $\mathrm{T}=120^{\circ}$, in a way which can be approximately described by an activated law (Figure 5 , bottom panel). The activation energy $E_{a} \approx 60 \mathrm{~kJ} /$ mole which best fits this exponential law is in agreement with other values quoted in the literature for amorphous silica ${ }^{3,6}$, although the latter were deduced from the temperature dependence of the global reaction rate constants.

\section{B. Formation of oligomers in the aqueous solution}

When a supersaturation is established in an aqueous solution, fluctuations of density induce the condensation and dissolution of small oligomers, with a finite life-time. These small units, called pre-nucleation clusters $^{49}$, have been thoroughly studied in the case of silica-rich solutions, both experimentally ${ }^{11-18}$ and theoretically ${ }^{19,21,50-52}$. It has been shown that their average concentration depends on several factors such as temperature, initial silica concentration, $\mathrm{pH}$ and the presence of additional cations. In particular, their amount largely differs according to whether alcoxides compounds are used, such as in the Stöber method ${ }^{53}$, or not. We will not discuss this latter case in the following but rather focus on conditions closer to those prevailing in the experimental conditions that we have considered in this work.

To summarize the main trends which are relevant around neutral $\mathrm{pH}$, it is found that, at constant temperature, the concentration of oligomers gets larger when the silica concentration in the aqueous solution increases, while, at constant silica concentration, it decreases when temperature is raised. Close to normal conditions of temperature and pressure, one essentially finds monomers together with a small percentage of dimers. The authors of
Ref. 4 have analyzed the percentage of oligomers present in solutions with $c_{\mathrm{SiO}_{2}}=500 \mathrm{ppm}$, at different temperatures, close to the period of maximum reaction rate. They found that, between $\mathrm{T}=30^{\circ} \mathrm{C}$ and $\mathrm{T}=120^{\circ} \mathrm{C}$, the dimer percentage decreases from $7 \%$ to $3.5 \%$, while that of trimers varies from $1 \%$ to $0.1 \%$ and heavier oligomers are less that $0.3 \%$.

Under the conditions that we have searched to reproduce, the role of dimers can thus only be invoked at low temperature and for the highest supersaturations. In the absence of speciation data for silica dimers in the aqueous solution, at $T=30^{\circ} \mathrm{C}$, we have deduced the equilibrium constant $K_{D}$ of the dimer formation from two monomers:

$$
2 \mathrm{H}_{4} \mathrm{SiO}_{4} \longrightarrow \mathrm{H}_{6} \mathrm{Si}_{2} \mathrm{O}_{7}+\mathrm{H}_{2} \mathrm{O}
$$

from the experimental $7 \%$ dimer percentage at $\mathrm{T}=30^{\circ} \mathrm{C}$ and total silica content $c_{\mathrm{SiO}_{2}}=500 \mathrm{ppm}$. The value $K_{D}=4.87$ results. Figures 6 compare the time dependence of the saturation state of the aqueous solution and of the mean particle radius, taking or not into account the presence of dimers. They show a very weak influence of the latter, which only induces a slightly more rapid decrease of $I(t)$ and $\mathrm{a} \approx 10 \%$ increase of the particle radii. Considering the weakness of these effects in the experimental conditions where they should be the highest, we can safely conclude that, taking them into account would have significantly modified neither the growth law that we have assumed, nor the parameter values of the model.

The role of oligomers in the precipitation of amorphous silica has often been invoked to rationalize reaction rate orders larger than 1. In particular, in Refs. 4 and 7, reaction orders equal to 4 have been assigned to a mechanism of condensation of tetramers, although it was obvious from the above mentioned data of Ref. 4 that the percentage of tetramers in the aqueous solution was extremely low. A fortiori, as far as the growth law exponent $m=6$ that we have determined is concerned, in no case can it be explained by a specific role played by hexamers. We have presently no explanation for this exponent value. The only thing that can be said here is that the maximum reaction rate is driven by the globality of the $\{$ nucleation + growth $\}$ processes. Indeed it is measured for values of $I$ larger than the critical saturation state $I_{c}$, where new particles keep being created. The maximum reaction rate exponent has thus no reason to be equal to the growth law exponent (Equation 7), which is confirmed by the fact that we reproduce a global reaction rate exponent equal to 4 with a growth rate exponent equal to 6 .

\section{Mechanism of amorphous silica precipitation}

We now focus on the information brought by our approach on the mechanism of amorphous silica formation. We first challenge the existence of an induction time, then we decipher the origin of the saturation plateaus found when an initial supersaturation is imposed. Finally, we 

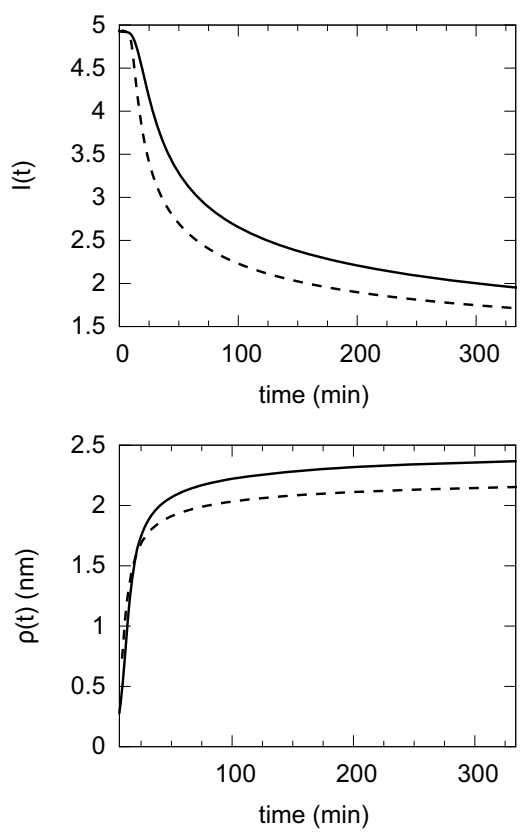

FIG. 6: Comparison of precipitation dynamics taking (full lines) or not (dashed lines) into account the presence of silica dimers $\mathrm{H}_{6} \mathrm{Si}_{2} \mathrm{O}_{7}$ in the aqueous solution. Top panel: variation of the saturation state $I$ of the aqueous solution as a function of time (in minutes). Bottom panel: variation of the mean particle radius $\rho$ (in $\mathrm{nm}$ ) as a function of time (in minutes). $\mathrm{T}=30^{\circ} \mathrm{C}$ and $I_{0}=4.9$.

discuss the characteristics of the particle population in the various types of experiments.

\section{Induction period}

In a number of works, authors refer to the existence of an induction period before the beginning of nucleation, because, either they observe a saturation plateau ${ }^{3,4,7}$ or they detect no particles ${ }^{10}$ during a given amount of time. In the framework of crystal growth theory, induction times are produced by non-stationary nucleation processes. In this section, we discuss which characteristics are to be expected within the non-stationary nucleation theory developed long time ago by Kaishev ${ }^{34,54}$ and conclude that they cannot account for the saturation plateaus under the conditions considered in this work.

When supersaturation is established in an aqueous solution, the formation of critical nuclei takes place as a result of density fluctuations, which induce a transient kind of random walk of the nuclei on the size axis (prenucleation clusters), up to the moment they reach their critical size. During this transient time, the supersaturation $I_{0}$ keeps a nearly constant value. Frenkel and Zeldovich ${ }^{34,55}$ analyzed this process and proposed a differential equation driving the time evolution of the con-

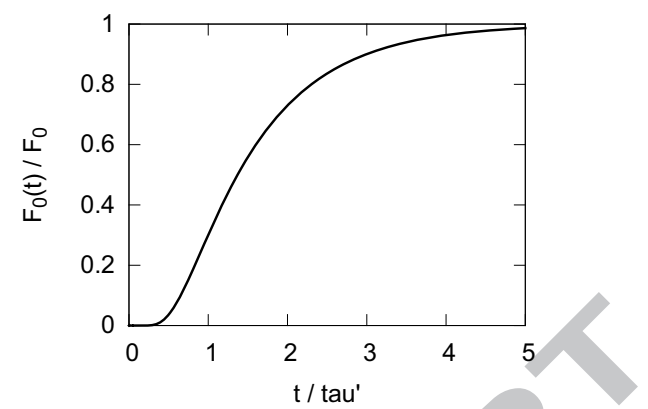

FIG. 7: Time dependence of the non-stationary nucleation rate $F_{0}(t)$, normalized to its steady state value $F_{0}$, as a function of $t / \tau^{\prime}$, deduced from Equation 10 .

centrations of nuclei as a function of their size. This equation was later solved by Kaishev ${ }^{54}$, who obtained the following expression for the non-steady state nucleation rate:

$$
F(t)=F_{0}\left[1+2 \Sigma_{m=0}^{+\infty}(-1)^{m} \exp \left(-t m^{2} / \tau^{\prime}\right)\right] \exp ^{-\frac{\Delta G^{*}}{k_{B} T}}
$$

Compared to Equation 5, the prefactor $F_{0}(t)$ of the exponential is time dependent with a characteristic time $\tau^{\prime}$ (induction time) related to $I_{0}$ by:

$$
\tau^{\prime} \propto \frac{1}{I_{0} * \ln ^{2} I_{0}}
$$

The time evolution of $F_{0}(t) / F_{0}$, represented on Figure 7 , shows that steady state of nucleation $\left(F_{0}(t) / F_{0}=1\right)$ is only reached after $t \approx 5 \tau^{\prime}$.

If the plateaus did represent induction times, according to Equation 11, their length $\Delta t$ would be proportional to $\tau^{\prime}$. $\Delta t$ would thus decrease at higher $I_{0}$ and vary as the inverse of $I_{0} * \ln ^{2} I_{0}$. While the general trend is observed, the relationship to $I_{0}$ is far from being quantitatively obeyed. Despite some unavoidable imprecision when reading $\Delta t$ in the Figures of Ref. 4 , there is a huge discrepancy of $\Delta t * I_{0} * \ln ^{2} I_{0}$ from a constant value. For example, between the highest and the lowest initial supersaturations, $\Delta t * I_{0} * \ln ^{2} I_{0}$ varies by a factor of $\approx 20$ at $\mathrm{T}=30^{\circ} \mathrm{C}$, a factor of $\approx 10$ at $\mathrm{T}=90^{\circ} \mathrm{C}$, and a factor of $\approx 20$ at $\mathrm{T}=180^{\circ} \mathrm{C}$. One may thus safely conclude that the saturation plateaus in these experiments cannot be attributed to an induction period and that another mechanism is at work.

Similarly, in the experiment at $c_{\mathrm{SiO}_{2}}=640$ ppm performed in Ref. 10, the 60 min delay in observing the first particles by SAXS cannot represent an actual induction time, since, at that time, the saturation state of the aqueous solution has already decreased by more than a factor of 2. The explanation thus more likely lies in the limit of detection of SAXS (particle radius larger than $1.5 \mathrm{~nm}$ ), as also suggested by the authors. 


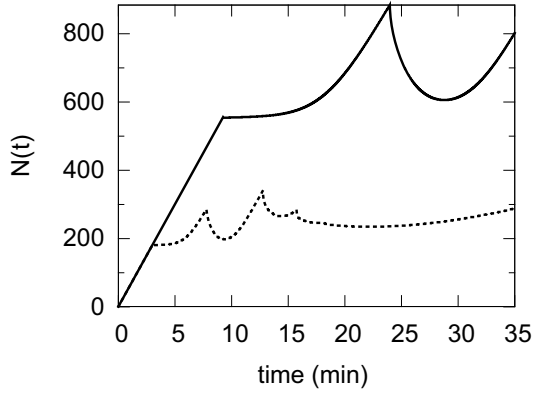

FIG. 8: Time evolution of the number of particle classes $N(t)$ during the first $35 \mathrm{~min}$ of the simulation of amorphous silica precipitation at $\mathrm{T}=30^{\circ} \mathrm{C}$ and $I_{0}=3.95$ (full line) and $I_{0}=4.6$ (dotted line).

\section{Saturation plateaus}

In the formalism underlying our simulations, nonstationary nucleation effects are not included. However, well-defined saturation plateaus are found when an initial supersaturation $I_{0}$ is imposed, especially at low initial $I_{0}$ (Figure 1), with a dependence of their length upon $I_{0}$ in agreement with experiment. These plateaus present some specific features:

- At constant $\kappa$ value, their relative lengths for various $I_{0}$ are strongly dependent on the critical supersaturation $I_{c}$, i. e. on the nucleation parameters. As $I_{c}$ increases, the plateau lengths associated to the smallest supersaturations increase much more than those associated to highest ones.

- During the plateau length $\Delta t$, there are particles which are formed, which grow or which dissolve. To exemplify these processes, Figure 8 displays the time evolution of the number of particle classes $N(t)$ which are present at $\mathrm{T}=30^{\circ} \mathrm{C}$ during the first 35 min of the simulation of amorphous silica precipitation. During this time, $I$ remains virtually equal to $I_{0}$. The first linear increase of $N(t)$ reveals that a new class is formed at each time step. The interruption of the linear variation marks the total dissolution of some classes. It occurs sooner at higher $I_{0}$ due to the larger growth rate (Equation 7). The maxima and minima in $N(t)$ evidence the competition between creation and destruction events of particle classes. However, the net balance corresponds to a very small amount of solid phase, typically $0.05-0.1$ mmole, too small to induce a visible decrease in the monomeric silica content.

All these features clearly indicate that the plateau period is not at all a period of time during which nothing happens, but that it rather corresponds to a competition between nucleation/growth/ dissolution processes. Indeed, nucleation takes place whenever $I>I_{c}$ and not only at time $t=0$. For example, at $\mathrm{T}=30^{\circ} \mathrm{C}$ and $I_{0}=4.6$, new particles are nucleated during about 4 hours. Once nucleated, these particles may experience growth or dissolution (Ostwald ripening), according to the relative value of their radius and the instantaneous critical radius. Nucleation and growth events impoverish the aqueous solution in monomers, while dissolution supplies monomers to it. The net balance nearly exactly vanishes during some period of time as far as the aqueous solution saturation state is concerned, although, when looking carefully at the values of $I$, one may see that it displays tiny fluctuations on the plateaus (not visible at the scale of Figure 1) . It is clear that precipitation models assuming that nucleation and growth are successive stages $^{23-26}$ (1) would find an immediate decrease of the saturation state of the aqueous solution in the nucleation period, except if they impose the size of critical nuclei to be zero, and (2) would never be able to produce plateaus in the saturation curves. Moreover, precipitation models which do not include Ostwald ripening would not be able either to produce such plateaus. The existence of plateaus, with lengths strongly dependent on the initial supersaturation, thus highlights the coexistence of nucleation and growth and the efficiency of Ostwald ripening already in the early stages of precipitation. It is a strong test of the validity of the precipitation models.

\section{Characteristics of the particle population}

Most simplified models of precipitation treat the particle population in an extremely simplified way. They generally assume that all particles are formed at time $t=0$ and have the same size. Furthermore, they assume that the particle sizes evolve in time according to a simplified law which does not take into account Ostwald ripening processes. We wish to show here, that in our more advanced modeling, the composition and evolution of the particle population is much more complex, and is strongly dependent on the thermodynamic conditions responsible for the precipitation.

Under conditions of pre-established supersaturation, nuclei are formed during the plateau period as well as during the saturation decrease which follows, until $I$ becomes less than $I_{c}$. However their number and fate is very dependent on the precise time of their nucleation, as illustrated in Fig. 9 (top panel), which represents the particle Size Distribution Function (SDF) $P(\rho)$ (i.e. the probability of finding particles with a radius bracketed by $\rho$ and $\rho+d \rho$ ) for precipitation at $\mathrm{T}=30^{\circ} \mathrm{C}$ and $I_{0}=4.6$. At the end of the plateau period $(t=950 \mathrm{~s}$, black SDF $)$, there are two families of particles which have nucleated at different times $([420-520] \mathrm{s}$ and [760-950] s, for the smallest and biggest ones, respectively). Later on, close to the time of maximum reaction rate $(t=6000 \mathrm{~s}$, medium grey SDF), the first family has completely disappeared and the particles of the second family have grown. There are also small particles (with radii in the $\AA$ range) nucle- 

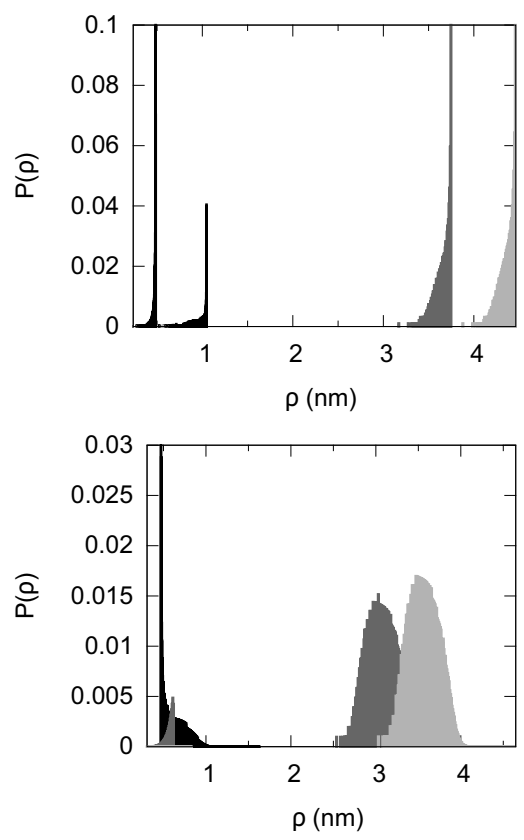

FIG. 9: Particle size distribution functions $P(\rho)$ at three times of the precipitation process (horizontal axis: radius $\rho$ in $\mathrm{nm}$ ). Top panel: an initial supersaturation $I_{0}=4.6$ is imposed at $\mathrm{T}=30^{\circ} \mathrm{C}$. The black, medium grey and light grey SDFs correspond to $t=950 \mathrm{~s}, t=6000 \mathrm{~s}$ and $t=60000 \mathrm{~s}$, respectively. Bottom panel: supersaturation is reached by $\mathrm{pH}$ drop in the conditions of Figure 3 with $c_{\mathrm{SiO}_{2}}=640 \mathrm{ppm}$. The black, medium grey and light grey SDFs correspond to $t=240 \mathrm{~s}$, $t=2400 \mathrm{~s}$ and $t=7200 \mathrm{~s}$, respectively.

ated during the saturation decrease $(t \epsilon[4740-6000] \mathrm{s})$, but their number is so small that their contribution is not visible at the scale of Figure 9. They have dissolved in the last plot of Fig. 9 (top panel), which is recorded at $t=60000 \mathrm{~s}$ (light grey SDF) when the saturation of the aqueous solution has become less than $I_{c}$. Again, at this time, there remain small particles (in the $\AA$ range) nucleated just before $I<I_{c}$ in negligible number, which will later disappear. The main contribution to the SDF remains the particle family nucleated at [420-520] $\mathrm{s}$ in the plateau period. This scenario is consistent with the analytic argument developed in one of our previous works ${ }^{28}$, which proved that particles nucleated when $d I / d t<0$ immediately decrease in size. Thus, only particles nucleated during the plateau period, when small saturation fluctuations occur and $d I / d t>0$, can survive in the long term, and among them, only the biggest ones, due to Oswald ripening.

The scenario is substantially different when supersaturation is progressively reached, whether by neutralization or cooling (and this is also true if supersaturation is induced by the dissolution of primary minerals ${ }^{29}$ ), although the growth and dissolution of particles obey the same laws as just discussed. For example, in Fig. 9 (bottom panel), are shown the SDFs at three different times during the precipitation of amorphous silica induced by a $\mathrm{pH}$ gradient at $\mathrm{T}=25^{\circ} \mathrm{C}$ and $c_{\mathrm{SiO}_{2}}=640 \mathrm{ppm}$. The SDF taken at the shortest time close to the maximum of supersaturation $(t=240 \mathrm{~s}$, black SDF) involves the particles nucleated between the time when $I$ has reached $I_{c}$ and $t$. The smallest ones, which are the most numerous, were nucleated when $I$ was the highest, i. e. at time $t$. This is consistent with the way the nucleation frequency and the critical nucleus sizes scale with $I$ (Equations 2 and 5), and explains the right skew shape of the SDF. At later times $(t=2400 \mathrm{~s}$, medium grey SDF, and $t=7200$ $\mathrm{s}$, light grey SDF), the smallest particles have dissolved. The SDFs are more symmetric and their center of gravity (mean particle radius) is shifted towards larger sizes. At $t=2400 \mathrm{~s}$, the particles of mean radius $0.6 \mathrm{~nm}$ which constitute the smallest SDF peak, have been created just before $t$, but they are due to disappear later on, since they were nucleated when $d I / d t<0$.

As a whole, if the rise of $I$ is fast enough, the main contribution to the particle population comes from particles nucleated in a very short time interval when the external thermodynamic conditions ( $\mathrm{pH}$ or $\mathrm{T}$ ) were rapidly changing. This may be the reason why the Chronomal model, which assumes that nucleation proceeds as a single rapid event followed by growth, was so successful in the interpretation of the experiments of Ref. 9. Nevertheless, it could be applied only in cases where the extent of crystallization is complete and was unable to predict the final size of the particles, which had to be taken from the experimental results. At variance, our modeling has shown that the final particle sizes are dependent on the precise evolution of the thermodynamic conditions during the short time when supersaturation is being reached.

This discussion shows that the precipitation process is much more complex than assumed by simple models, and that the composition and evolution of the particle population presents distinctive features, function of the thermodynamic conditions of precipitation.

\section{CONCLUSION}

We have applied an advanced simulation technique to decipher the microscopic mechanism of amorphous silica precipitation, beyond empirical approaches used in the past. Our approach, embedded into the NANOKIN code, fully accounts for nucleation and involves a sizedependent growth law able to produce Ostwald ripening effects. The time evolution of the particle population and of the aqueous solution composition and speciation are consistently treated via a feed-back loop.

Based on this approach, we have shown that it is possible to quantitatively reproduce the results of precipitation experiments performed either by imposing a preestablished supersaturation to an aqueous solution, or creating it by rapid neutralization or cooling. The parameters of the model which allow to best reproduce experimental results display variations with temperature in 
accordance with propositions of the literature (activated law for the growth constant and correlation with the evolution of the solubility product for the interface energy). A growth law of order 6 was necessary to account at the same time for the plateau lengths and maximum reaction rates. Under the experimental conditions that we have simulated, this cannot be explained by the presence of oligomers in the aqueous solution, nor can the latter substantially modify the precipitation dynamics.

We have discussed several characteristics of the precipitation processes. Relying on Kaishev's theory of nonstationary nucleation, we have discarded the hypothesis of an induction time as an explanation for the plateaus observed in the saturation curves. We have shown that the latter rather result from a competition between nucleation, growth, and dissolution of particles which take place simultaneously. We have also studied the characteristics of the particle population and shown that they were much more complex than generally assumed by simple models of precipitation and strongly dependent on the way supersaturation is reached. Such a microscopic approach thus proves to be well suited to elucidate the mechanism of nanoparticle formation in natural and industrial contexts.

\section{ACKNOWLEDGEMENTS}

We are grateful to D. Tobler who drew our attention to her 2009 work and to D. Tobler and L.G. Benning for a very fruitful discussion. We also acknowledge enlightening discussions with A. Baronnet.
1 I. Gunnarsson, S. Arnorsson, Silica scaling: The main obstacle in efficient use of high-temperature geothermal fluids, International Geothermal Conference, Reykjavik, 2003.

2 R. K. Iler, The Colloid Chemistry of Silica and Silicates, Cornell University Press, Ithaca, New York, 1979.

3 S. Carroll, E. Mroczek, M. Alai and M. Ebert, Geochim. Cosmochim. Acta 62 (1998) 1379.

${ }^{4}$ H. P. Rothbaum, A. G. Rohde, J. Colloid Interf. Sci. 71 (1979) 533

5 A. C. Makrides, M. Turner and J. Slaughter, Journal of Colloid and Interface Science 73 (1980) 345.

6 J. D. Rimstidt, H. L. Barnes, Geochim. Cosmochim. Acta 44 (1980) 1683

7 G. A. Icopini, S. L. Brantley and P. J. Heaney, Geochim. Cosmochim. Acta 69 (2005) 293.

8 C. F. Conrad, G. A. Icopini, H. Yasuhara, J. Z. Bandstra, S. L. Brantley and P. J. Heaney, Geochim. Cosmochim. Acta 71 (2007) 531.

9 D. J. Tobler, S. Shaw, L. G. Benning, Geochim. Cosmochim. Acta 73 (2009) 5377.

10 D. J. Tobler, L. G. Benning, Geochim. Cosmochim. Acta 114 (2013) 156.

11 J. P. Jolivet, M. Henry, De la Solution à l'Oxyde, J. Livage, EDP Science, 1994.

12 R. H. Busey, R. E. Mesmer, Inorg. Chem. 16 (1977) 2444

${ }^{13}$ L. W. Cary, B.H.W.S. de Jong, W. E. Dibble Jr., Geochim. Cosmochim. Acta 46 (1982) 1317.

14 S. D. Kinrade, T. W. Swaddle, Inorg. Chem. 27 (1988) 4253.

15 C. T. G. Knight, R. J. Kirkpatrick, E. Oldfield, J. Chem. Soc., Chem. Comm. 14 (1989) 919.

16 S. Sjöberg, Journal of non-crystalline solids 196 (1996) 51.

17 N. Zotov, H. Keppler, Chemical Geology 184 (2002) 71.

18 T. V. Gerya, W. V. Maresch, M. Burchard, V. Zakhartchouk, N. L. Doltsinis, T. Fockenberg, Eur. J. Mineral. 17 (2005) 269.

19 S. Caratzoulas, D. G. Vlachos, J. Phys. Chem. B 112 (2008) 7 .

20 J. D. Hunt, A. Kavner, E. A. Schauble, D. Snyder, C. E.
Manning, Chemical Geology 283 (2011) 161.

${ }^{21}$ X.-Q. Zhang, T. T. Trinh, R. A. van Santen, A. P. J. Jansen, J. Am. Chem. Soc. 133 (2011) 6613.

${ }^{22}$ See Table 1 in Ref.9 for a summary of previous works.

23 M. Avrami, I. J. Chem. Phys. 7 (1939) 1103.

24 M. Avrami, II. J. Chem. Phys. 8 (1940) 212.

${ }^{25}$ P. F. Johnson and R. F. Mehl, Reaction kinetics in processes of nucleation and growth, A. I. M. E. Tech. Pubs., 1939.

26 A. E. Nielsen, Acta Chimica Scandinavica 13 (1959) 784.

27 C. Noguera, B. Fritz, A. Clément and A. Baronnet, J. Cryst. Growth 297 (2006) 180.

28 C. Noguera, B. Fritz, A. Clément and A. Baronnet, J. Cryst. Growth 297 (2006) 187.

${ }^{29}$ B. Fritz, A. Clément, Y. Amal and C. Noguera, Geochim. Cosmochim. Acta 73 (2009) 1340.

30 B. Fritz, A. Clément, and C. Noguera, CrystEngComm 15 (2013) 3392.

31 H.C. Helgeson, T. H. Brown, A. Nigrini and T. A. Jones, Geochim. Cosmochim. Acta 34 (1970) 455.

32 D. L. Parkhurst and C. A. J. Appello, User's guide to PHREEQC (Version 2), U.S. Department of the Interior, U.S.G.S., 1999.

33 A. W. Adamson, Physical chemistry of surfaces, Interscience Publishers, 1960.

${ }^{34}$ I. V. Markov, Crystal growth for Beginners: fundamentals of nucleation, crystal growth and epitaxy, World Scientific, Singapore, New Jersey, London, Hong Kong, 1995.

35 O. R. Myhr, O. Grong, Acta Mater. 48 (2000) 1605

${ }^{36}$ L. Ratke, P. W. W. Voorhees, Growth and Coarsening: Ostwald Ripening In Material Processing, Springer, Germany, 2002.

37 Note that it would not be the case if the growth law had been written as $\left[I-\exp \left(\frac{w}{\rho}\right)\right]^{m}$ with an even value for $m$

38 I. Gunnarsson and S. Arnórsson, Geochim. Cosmochim. Acta 64 (2000) 2295.

39 P. Van Cappellen, The formation of marine apatite: a kinetic study, Ph. D. dissertation, Yale Unversity, 1990.

40 R. O. Fournier and J. J. Rowe, Am. J. Sci. 64 (1966) 685. 
41 J. Ganor, T.J Hudson, L.M. Walter, Geochim. et Cosmochim. Acta 69 (2005) 275.

${ }^{42}$ We note that, in Refs. 9,10, it is not obvious whether the saturation state at time $t=0$ has been measured or put equal to the nominal value associated to the initial silica content of the aqueous solution.

43 C. C. Perry, T. Keeling-Tucker, J. Biol. Inorg. Chem. 5 (2000) 537.

${ }^{44}$ L. Mazeina, S. Deore, A. Navrotsky, Chem. Mater. 18 (2006) 1830.

45 A. Navrotsky, J. Chem. Thermodynamics 39 (2007) 2.

46 J. Majzlan, L. Mazeina, A. Navrotsky, Geochim. Cosmochim. Acta 71 (2007) 615.

47 J. P. Jolivet, C. Froidefond, A. Pottier, C. Chaneac, S. Cassaignon, E. Tronc, P. Euzin, J Mater Chem 14 (2004) 3281.
48 A. E. Nielsen and O. Söhnel, J. Cryst. Growth 11 (1971) 233.

49 D. Gebauer, M. Kellermeier, J. D. Gale, L. Bergström, H. Cölfen, Chem Soc. Rev. 43 (2014) 2348.

50 C. T. G. Knight, R. J. Balec, S. D. Kinrade, Angew. Chem. Int. Ed. 46 (2007) 8148.

51 C. E. White, J. L. Provis, T. Proffen, J. S. J. van Deventer, J. Phys. Chem. C 115 (2011) 9879.

52 G. J. McIntosh, Phys. Chem. Chem. Phys. 15 (2013) 3155 .

${ }^{53}$ W. Stöber, A. Fink, E. Bohn, J. Colloid Interf. Sci. 26 (1968) 62.

54 D. Kaishev, Sur. Sci. 14 (1969) 209.

55 J. I. Frenkel, Kinetic Theory of Liquids, Peter Smith Publisher, Incorporated, 1984. 


\section{ACCEPTED MANUSCRIPT}

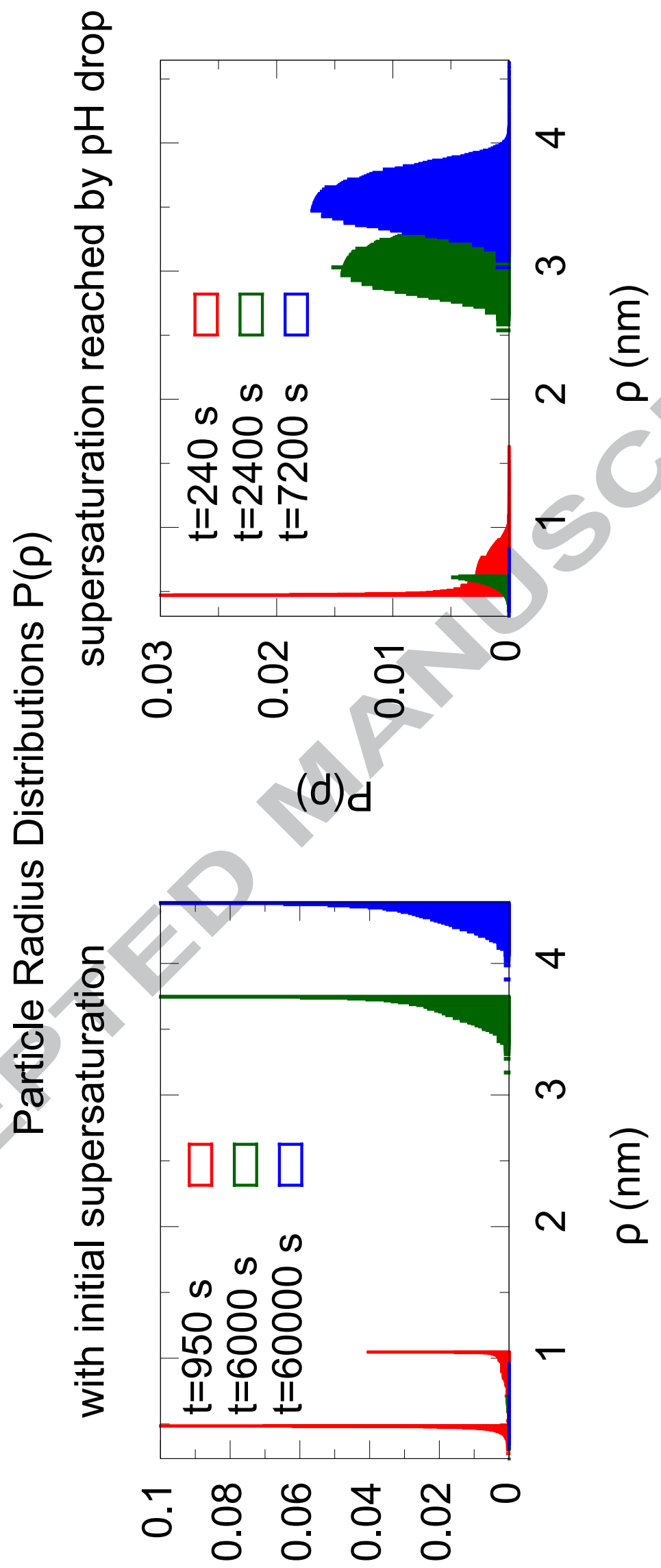

(d)d 
- An advanced simulation technique of amorphous silica precipitation is implemented

- Time evolution of particle population and solution composition is predicted

- Saturation plateaus are not due to an induction time

- Characteristics of particle population depend on how supersaturation is reached

- The simulation quantitatively reproduces a large range of previous experimental studies. 